\title{
MENTZER INDEX IN PEDIATRIC THALASSEMIA TRAIT
}

\section{Andreea Oltean ${ }^{1}$, Ioana Mihaela Chincesan ${ }^{2}$}

\section{Abstract}

Thalassemia is a group of inherited diseases of the blood that affect a person's ability to produce hemoglobin, resulting in anemia. The incidence of thalassaemia carriers is high in regions such as Mediterranean, Middle East, Indian subcontinent, Southeast Asia and South China. In the past few decades, migrants from the thalassaemia prevalent countries to non-prevalent countries, mainly North America and Central and North Europe, are rapidly increasing in number. The objective of this study is identifying the pediatric patients with beta thalassemia minor or thalassemia trait and the importance of differential diagnosis of minor thalassemia to a hypochromic anemia of another cause using Mentzer index. The study included 40 patients diagnosed with beta thalassemia minor and treated at the Pediatrics I Clinic of Târgu Mureş HematologyOncology Department during 2007-2017 and it demonstrates the efficacy of using the Mentzer index (MI) in medical practice.

Keywords: thalassemia, child, hemoglobin electrophoresis, Mentzer index

\section{Introduction}

Beta-thalassemia is a hereditary condition caused by low hemoglobin synthesis resulting in variable phenotypes ranging from severe anemia to clinically asymptomatic individuals. World Health Organization (WHO) has recognized thalassemia as the most common hematological genetic disorder in the world found in more than 60 countries and is very common among children in the Middle East, the Mediterranean and South Asia. In Romania the frequency of thalassemia is estimated at $5 \%$ $(1,2)$.

Thalassemia minor also called thalassemia trait can be clinically asymptomatic because only one beta-thalassemic gene is affected. Heterozygotes are carriers of this gene and may have moderate anemia. When both parents are carriers there is a $25 \%$ risk at each pregnancy of having children with homozygous thalassemia (3). Thus it is very important to identify cases of beta thalassemia minor because the mutation can be transmitted further or in the case of carriers there is the possibility that mothers give birth to homozygous children.

Thalassemia minor is characterized by reduced mean corpuscular volume (MCV) and mean corpuscular hemoglobin $(\mathrm{MCH})$, normal or low hemoglobin $(\mathrm{Hb})$, with increased $\mathrm{Hb}$ A2 level, normal/ increased iron level, increased ferritin level, moderately high indirect bilirubin. The peripheral blood smear shows microcytosis, hypochromia, anisocytosis, poikilocytosis. Carriers have less severe red blood count morphologic changes than affected individuals (4). Beta thalassemia minor is confirmed by $\mathrm{Hb}$ electrophoresis that highlights $\mathrm{HbA} 2>$ $3.5 \%$, low $\mathrm{HbA} 90-95 \%$, and $\mathrm{Hb} \mathrm{F}$ of $50 \%$. Typical betathalassemia carriers are identified by analysis of red blood cell (RBC) indices, which shows microcytosis (low MCV) and reduced content of $\mathrm{Hb}$ per red cell (low $\mathrm{MCH}$ ). MI index is used by clinicians as differential diagnosis between beta thalassemia minor and iron deficiency anemia; it is calculated dividing the MCV value to RBC value; thus MI $>13$ is raising a high suspicion of iron deficiency anemia and $\mathrm{MI}<13$ is raising a suspicion of thalassemia. When the hematologic analysis is abnormal, molecular genetic testing of beta globin gene is performed to identify the diseasecausing mutation (5). Fortunately, most cases of minor thalassemia do not require treatment. Supplementary folic acid can be prescribed to patients with thalassemia trait to prevent deficiency from hyperactive bone marrow. It is recommended to avoid iron supplements and foods that increase the amount of iron in the organism (6). Genetic counseling and genetic testing are recommended for families who carry a thalassemia trait (7).

People with $\beta$-thalassemia trait should be warned that their condition can be misdiagnosed as the more common iron deficiency anemia.Thus our aim was to identify the pediatric patients with beta thalassemia minor using MI and differentiate it from a hypochromic anemia of another cause.

\section{Material and method}

We conducted a retrospective and descriptive study that included 40 pts under the age of 18, diagnosed and treated at the Pediatrics I Clinic in Targu Mures, the Hematology-Oncology Department, during 2007-2017. The inclusion criteria was $\mathrm{Hb}$ A2 $>3.5 \%$. Also the following were observed: the number of erythrocytes, hemoglobin concentration, hematocrit, $\mathrm{MCV}$, reticulocytes and erythrocyte morphology, serum iron, level of $\mathrm{Hb} \mathrm{A}$, MI value. Also, gender, age at diagnosis, family and personal history of anemia, clinical signs of onset: abdominal pain, headache, jaundice.

${ }^{1}$ Mures County Emergency Hospital Târgu-Mureş

${ }^{2}$ University of Medicine, Pharmacy, Science and Technology Târgu-Mures; Pediatric Clinic I

E-mail: durlanandreea@yahoo.com,mchincesan@yahoo.com 
Table 1. Average, minimum and maximum values of laboratory analysis

\begin{tabular}{lccc}
\hline $\begin{array}{l}\text { Other Laboratory } \\
\text { Analysis }\end{array}$ & $\begin{array}{c}\text { Maximum } \\
\text { value }\end{array}$ & $\begin{array}{c}\text { Mean } \\
\text { value }\end{array}$ & $\begin{array}{c}\text { Minimum } \\
\text { value }\end{array}$ \\
\hline RDW (\%) & 33.1 & 18.22 & 13 \\
\hline Reticulocytes (\%) & 92 & 28.52 & 8 \\
\hline Serum Iron (qmol/L) & 34.59 & 15.31 & 2.31 \\
\hline
\end{tabular}

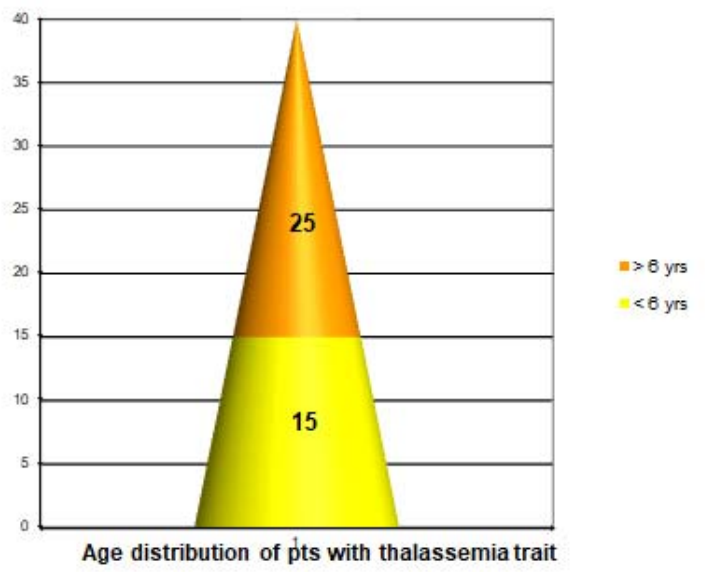

Fig. 1. Age distribution

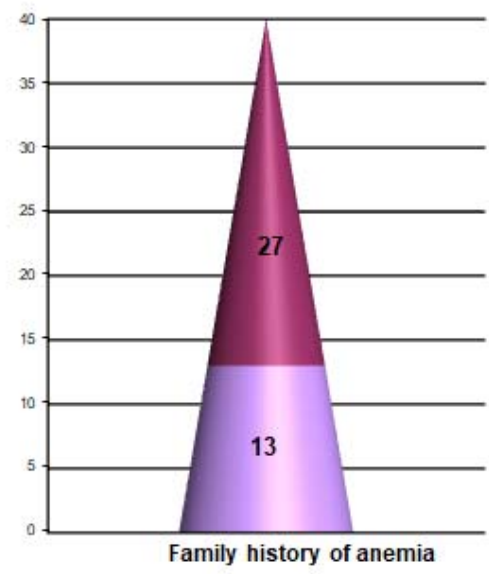

- pozitive history "w negative history

Fig. 2 a and b. History of anemia

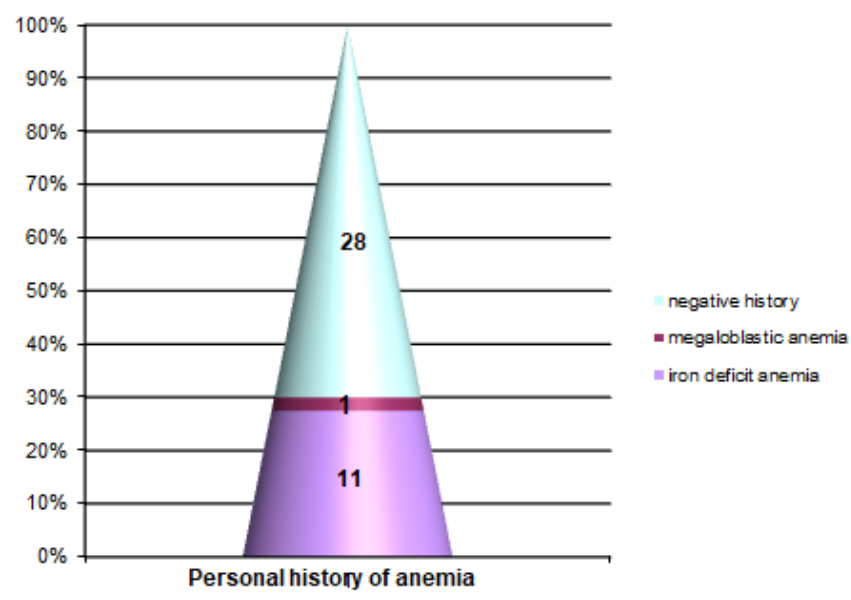




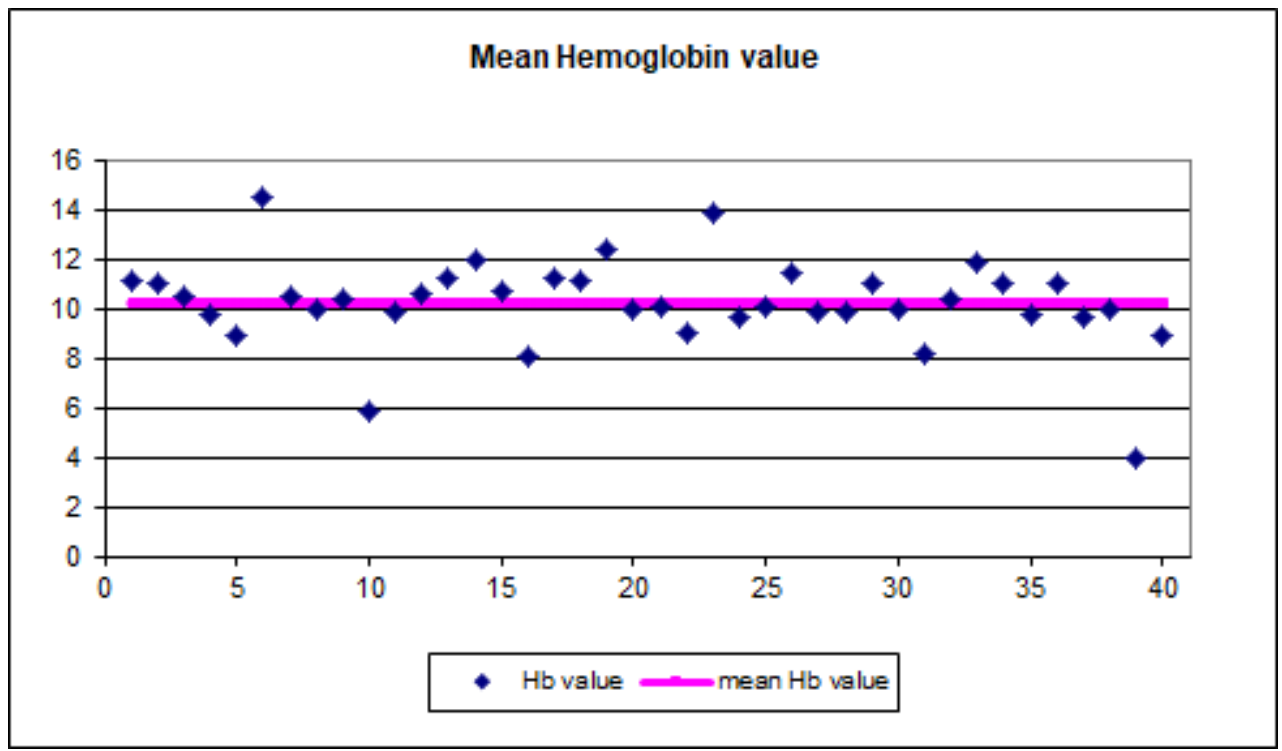

Fig. 3. Hemoglobin value

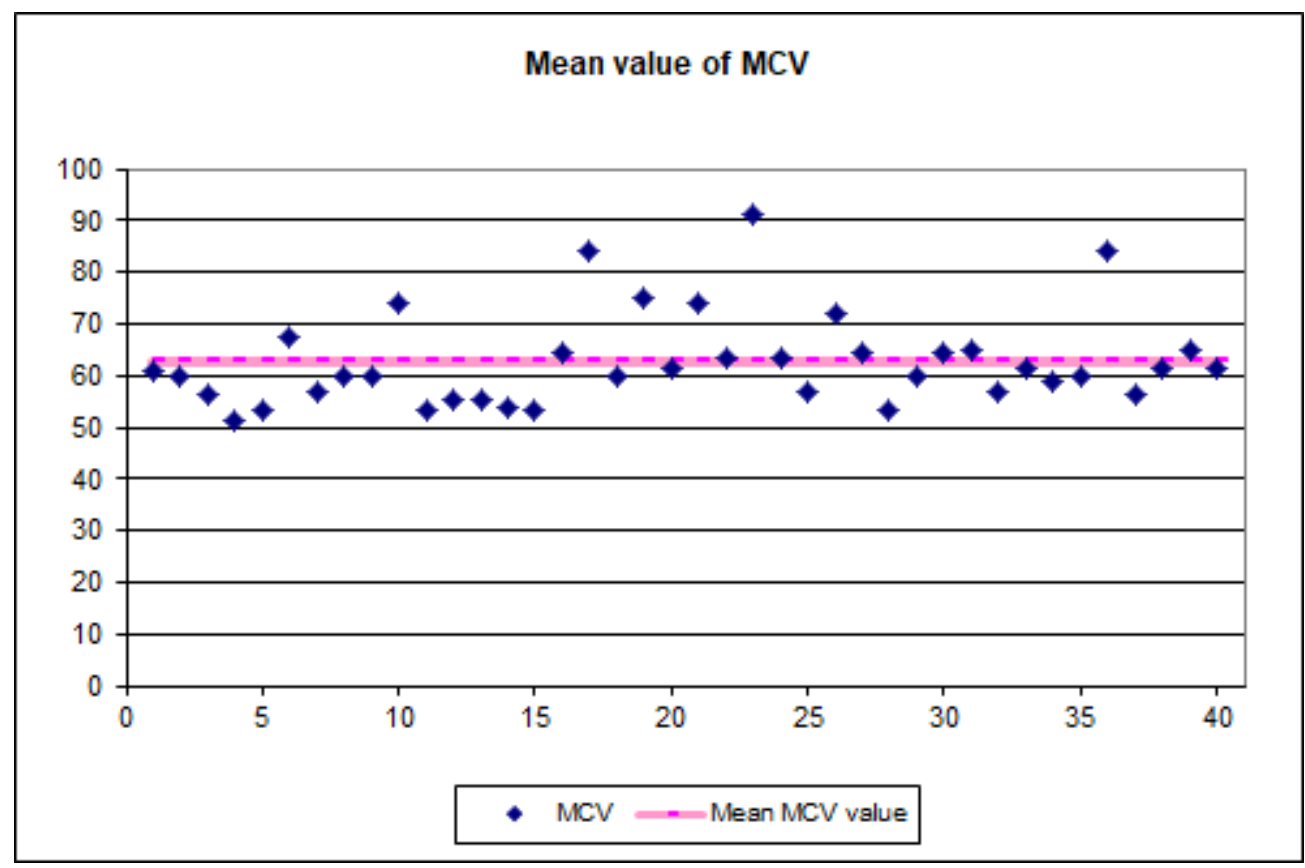

Fig. 4. MCV value 


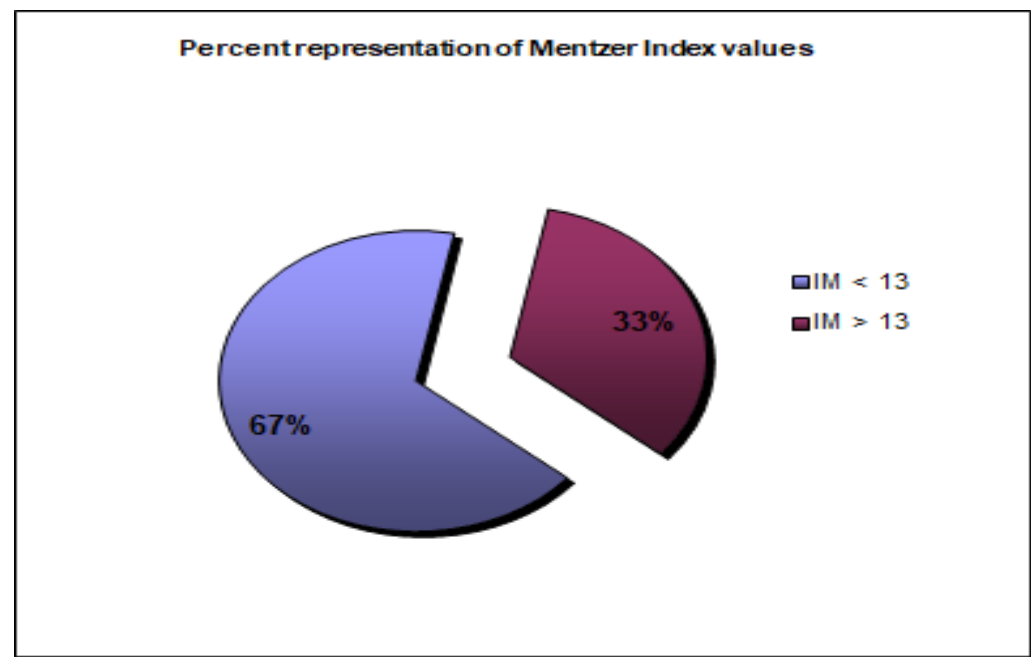

Fig. 5. Metzer index

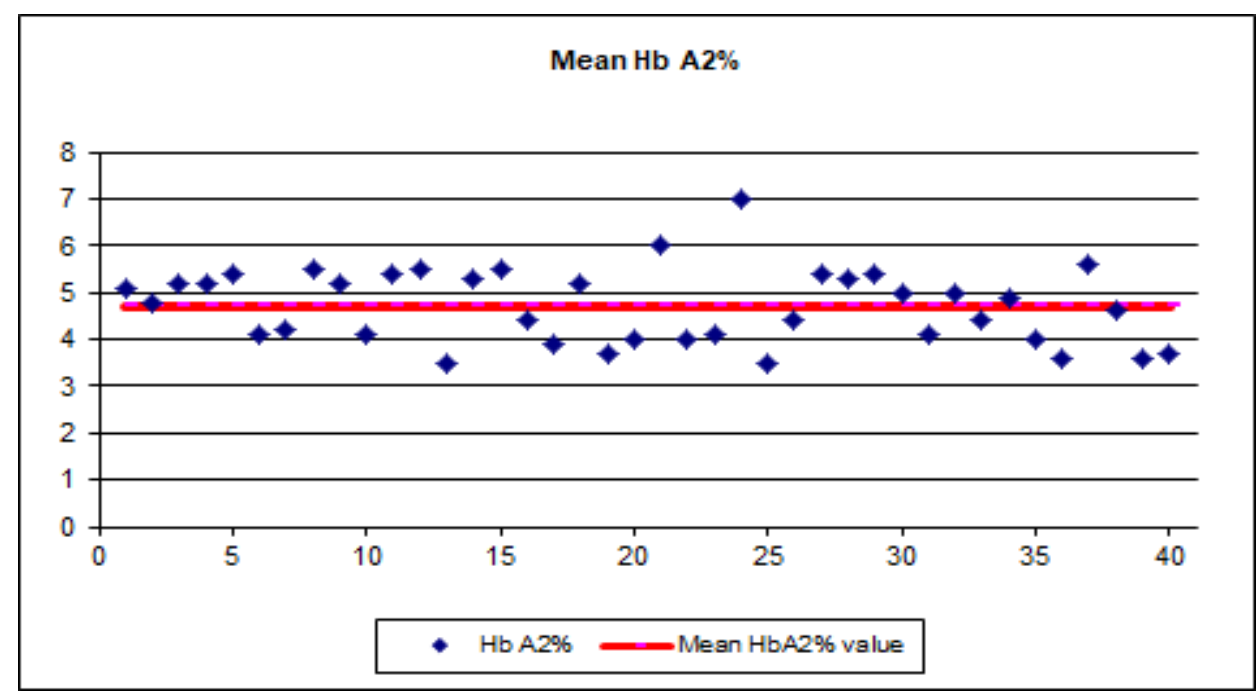

Fig. 6. $\mathrm{Hb} \mathrm{A} 2 \%$

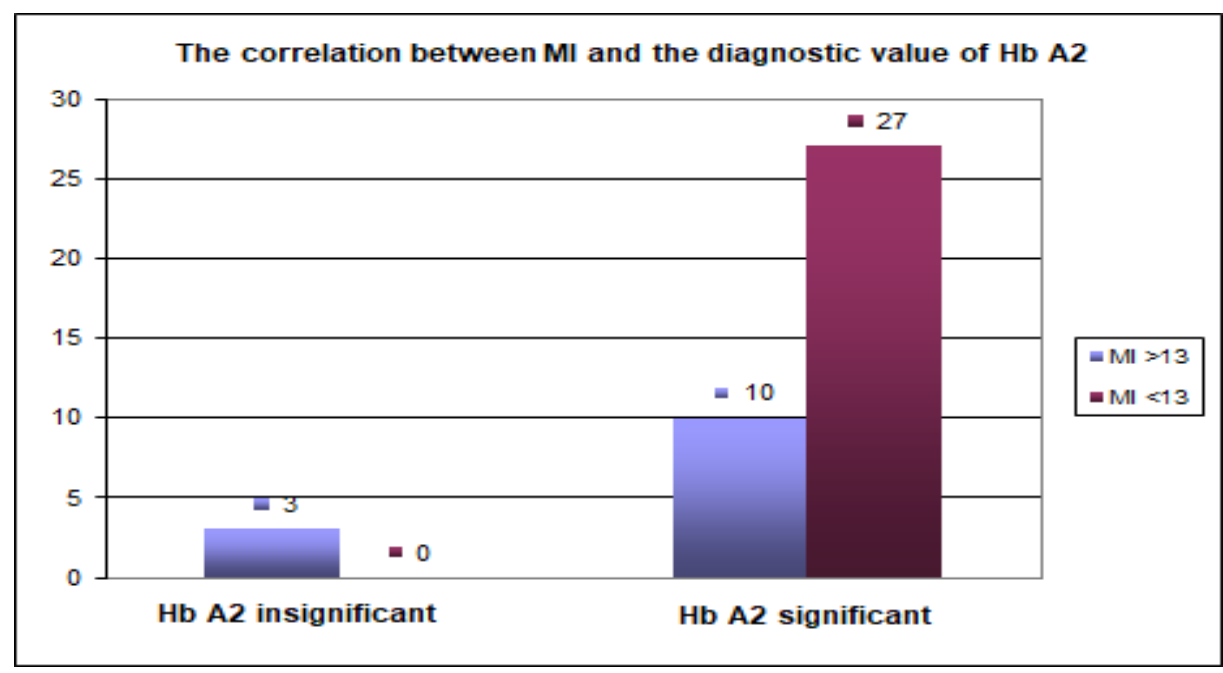

Fig. 7. Correlation $\mathrm{MI}$ and $\mathrm{Hb} \mathrm{A} 2$ 


\section{Results and discussions}

Through this study we have attempted to demonstrate that by carefully analyzing hematological parameters of the $\mathrm{CBC}$ and calculating a single index, we can orientate ourselves to a correct diagnosis and avoid the inappropriate treatment of a patient with an alleged iron deficit anemia.

The distribution of patients (pts) according to gender revealed 24 girls and 16 boys. Although literature describes an equal gender distribution, we noticed a slight predominance in females $(60 \%)$ versus males (40\%) (7). Beta thalassemia minor is poor in clinical signs and symptoms, which is why the diagnosis is often late, as it was found in this study; the mean age of pts enrolled at the time of diagnosis was 8.3 years, with a maximum of 18 years and a minimum of 6 months. We noticed that the number of cases diagnosed is more numerous at the age above 6 years (Figure 1).

Anamnesis and clinical examination are indispensable to establish a correct diagnosis. Patients need a thorough and complete assessment. In this study family history has a great importance because it can guide the doctor to a possible congenital anemia diagnosis. 27 pts had a positive family history for anemia of different types, from which 5 had first degree relatives diagnosed with minor thalassemia. 12 pts had a personal history of anemia, one had megaloblastic anemia (Figure 2a, b).

At the time of diagnosis, 36 pts showed clinical signs of onset, of which 22 pts had pale mucosa/skin, 9 pts abdominal pain, 3 pts headache and 2 pts had jaundice. A retrospective study in Korea between 2000 and 2011, where the incidence of thalassemia is very low, showed that the vast majority of children (78\%) tested for beta thalassemia were asymptomatic, they were accidentally diagnosed due to the fact that the complete blood count (CBC) was performed for another reason (8).

As for laboratory analysis, we observed that in $63 \%$ of patients the $\mathrm{CBC}$ showed a normal number of $\mathrm{RBC}$ and in only $5 \%$ cases the RBC was low. The mean of RBC values was 5.11 million $/ \mathrm{mm} 3$, with a minimum value of 2.13 million /mm3 and a maximum of 6.48 million $/ \mathrm{mm} 3$.

$\mathrm{Hb}$ was low in $38 \mathrm{pts}$; the mean $\mathrm{Hb}$ was $10.24 \mathrm{~g} / \mathrm{dL}$ (Figure 3). In a 2009 American article Claude O.B explains the easiest way to separate thalassemia trait and iron deficiency anemia is by simple inspection, bacause thalassemia trait rarely causes anemia of less than $10 \mathrm{~g} / \mathrm{dL}$ of hemoglobin (9).

The lowest value $\mathrm{Hb} 4 \mathrm{~g} / \mathrm{dL}$, was clinically manifested by severe anemia requiring $\mathrm{RBC}$ transfusion, in a patient associating megaloblastic anemia, this masked the diagnosis of beta thalassemia, at the time of diagnosis MCV was increased, after correction of vitamin B12 deficiency, microcytic anemia persisted with a hemoglobin value of $4 \mathrm{~g} / \mathrm{dL}$ and a erythrocyte count of 2.13 mil, calculating MI that was under 13, hemoglobin electrophoresis was performed for suspicion of minor beta thalassemia and, as a result, this hypothesis was confirmed.

$97 \%$ of pts had a low hematocrit value and only $3 \%$ had a normal value. MCV is a very important parameter in the diagnosis of microcytic anemia, in $95 \%$ patients $\mathrm{MCV}$ was below 80fl. As one of the most indicative parameters, we calculated its average value: $62.6 \mathrm{fl}$ with a maximum value of $90.6 \mathrm{fl}$ and a minimum value of $50.8 \mathrm{fl}$ (Figure 4). All 38 low MCV patients had characteristic erythrocyte morphology for thalassemia. A study from Pakistan suggests that careful monitoring of $\mathrm{CBC}$ parameters, including $\mathrm{RBC}$ indices and morphology, along with clinical findings are essential to diagnose carrier cases, especially in high prevalence areas (10).

All patients had a high number of reticulocytes, interpreted as an indicator of effective regenerative erythropoiesis; reticulocytosis is characteristic in beta thalassemia. From the group studied, we noticed that 26 of pts had normal iron levels, 9 pts had decreased iron levels, and 5 pts had increased iron levels. Iron overload is a major problem of beta thalassemia and it occurs more commonly in beta thalassemia major than in thalassemia trait, as described in a Romanian study. Also iron overload is considered a complication that appears in adult life, as in the study Tudor Arbanas et al describes in the Romanian study that all thalassemics without complications were younger than 25 years old, half of them being under 14 years old (11). Other laboratory tests are shown in table 1. Related to MI $67 \%$ of patients had an index under 13 (Figure 5). The results of our study on the utility of MI in diagnosing of thalassemia are consistent with other studies. With regard to the Mentzer index, several similar studies have concluded that this index is best suited to direct the diagnosis to a beta thalassemia. A retrospective study evaluated the safety of calculating various indicators for the diagnosis of microcytic anemia and beta thalassemia. This study was conducted on a group of 290 carefully selected children, calculating 12 indices that could suggest the diagnosis of thalassemia or iron deficiency anemia. Their conclusion was that MI is the safest among the 12 indices, with the highest sensitivity (98.7\%) and specificity $(82.3 \%)$, and also the easiest to use and accurate to detect a possible beta thalassemia, according to their results the percentage of correctly diagnosed patients was highest with the Mentzer index (91\%) (12).

$\mathrm{Hb}$ electrophoresis is the most important investigation to confirm the diagnosis; in the studied group all patients benefited from this analysis and the results of the $\mathrm{Hb}$ electrophoresis are presented in Figure 6. The mean $\mathrm{Hb}$ A2 is $4.72 \%$, with a minimum value of $3.6 \%$ and a maximum of $7 \%$. All patients who had HbA2 value of $>3.5 \%$ had a $\mathrm{MCV}<80 \mathrm{fl}$, high red cell distribution width (RDW) and a characteristic thalassemia smear. Statistically analyzing the correlation between $\mathrm{Hb} \mathrm{A} 2$ and the Mentzer index we obtained the following results: elevated levels of $\mathrm{Hb} \mathrm{A} 2$ confirming beta thalassemia minor, were correlated statistically significant with $\mathrm{MI}<13$ suggesting thalassemia $(\mathrm{p}=0.0289)$, (Figure 7). Also a statistically significant correlation with a $\mathrm{p}=0.0001$, was between the $\mathrm{MI}<13$ and the peripheral blood smear characteristics for the same pathology. Many studies attest the relevance of new indices such as Youden's Index in the diagnosis of thalassemia beta minor, also a Pakistan study found a new reliable parameter 
to differentiate between iron deficiency anemia and thalassemia trait $(13,14)$. Further studies must be made to establish whether one or more of these indices should be used in medical practice.

\section{Conclusions}

Beta thalassemia minor can be easily suspected based on routine hematological analysis when investigating other pathologies. This condition is often confused with iron deficit anemia because it has many clinical and paraclinical similarities or is underdiagnosed. Therefore iron supplements are often prescribed. Iron supplements may result in excess iron, which can collect in many areas of the body causing organ damage. Carriers should only take iron supplements if serum iron shows they are iron deficient. Most patients diagnosed our study are above 6 years old, this is probably due to poor clinical signs and symptoms of thalassemia trait. The most common indicators for thalassemia are: low $\mathrm{MCV}$, low $\mathrm{Hb}$, elevated iron levels, blood smear with microcytosis, and none the less $\mathrm{MI}<13$. This study demonstrates the effectiveness of using the Mentzer index in medical practice in patients with any type of anemia especially in case of beta thalassemia minor suspicion, but confirmation of diagnosis is possible by conducting hemoglobin electrophoresis, which is the gold standard for the diagnosis of beta thalassemia minor

\section{References}

1. Lancet. Global, regional, and national incidence, prevalence, and years lived with disability for 310 diseases and injuries, 1990-2015: a systematic analysis for the Global Burden of Disease Study 2015". GBD 2015 Disease and Injury Incidence and Prevalence, Collaborators. (2016) 388: 1545-1602.

2. Borgna-Pignatti C, Galanello R. Thalassemias and related disorders: quantitative disorders of hemoglobin synthesis In Lippincott Williams \& Wilkins; Wintrobe's Clinical Hematology. Philadelphia; Vol. 42, 2004: 1319-1365.

3. Swee Lay Thein. The Molecular Basis of Beta Thalassemia. Cold Spring Harb Prospect Med 2013, 3(5)

4. Idit L R, Boaz L, Guy K,Carina L, et al Detection of $\beta$ Thalassemia Carriers by Red Cell Parameters Obtained from Automatic Counters using Mathematical Formulas. Mediterr J Hematol Infect Dis. 2018; 10(1)

5. Vrettou C, Traeger-S J, Tzetis M, Malamis G, Kanavakis E. Rapid screening of multiple betaglobin gene mutations by real-time PCR on the LightCycler: application to carrier screening and prenatal diagnosis of thalassemia syndromes. Clin Chem. 2003;49:769776.

6. Samavat A, Modell B "Iranian national thalassaemia screening programme". BMJ. 2004.329 (7475): 1134-7.

7. Olivieri NF. The beta-thalassemias Med. N Engl J Med. 1999;341(18):1407.

8. Che R, Hyoung J K, Ji W L, Hyery K et al. Clinical Characteristics of Pediatric Thalassemia in Korea: A Single Institute Experience. J Korean Med Sci. 2013 Nov; 28(11): 1645-1649

9. Claude Owen Burdick. Separating Thalassemia Trait and Iron Deficiency by Simple Inspection Am J Clin Pathol, Volume 131, Issue 3, 2009:444-445,

10. Kandhro AH, Prachayasittikul V, Isarankura NC, Nuchnoi P.Prevalence of Thalassemia Traits and Iron Deficiency Anemia in Sindh, Pakistan. Hemoglobin. 2017;41(3):157-163.

11. Tudor A, Florentina Vl, Alice A; Mircea D, Different tissue sensitivity to iron induced toxicity defines the spectrum of complications in Romanian $\beta$-thalassemia major patients. JCM Vol 4 (7), No 3, 2009

12. Aysel V, Gamze O, Ayşegul DD, Selcuk U et al. Hematological Indices for Differential Diagnosis of Beta Thalassemia Trait and Iron Deficiency Anemia, Anemia. 2014; 2014: 576738.

13. Januária F. Matos, Luci M.S. Dusse, Karina B.G. Borges, Ricardo L.V. de Castro, et al A new index to discriminate between iron deficiency anemia and thalassemia trait. Rev Bras Hematol Hemoter. 2016 JulSep; 38(3): 214-219.

14. Tahir 1, Mukhtiar Bg, Ijaz Ad, Muhammad B Hn et al Differentiation of beta thalassemia trait from iron deficiency anemia by hematological indices Pak J Med Sci. $2017 \quad$ May-Jun; 33(3): 665-669.

Correspondence to:

Mihaela Ioana Chinceșan

Department of Pediatrics I

University of Medicine and Pharmacy Tîrgu-Mures

38 Gh Marinescu St, 540139, Romania.

Phone: $+40-740-478188$

Fax: +40-265-211098.

E-mail: mchincesan@yahoo.com 